Check for updates

Cite this: RSC Adv., 2017, 7, 35038

\title{
Selenoprotein SelK increases the secretion of insulin from MIN6 $\beta$ cells
}

\author{
Xue-Lian Meng, ${ }^{a}$ Hui-Ling Zhang, ${ }^{b}$ Lin-Lin Feng, ${ }^{b}$ Man-Ling Chen, ${ }^{a}$ Ying-Ying Liu, ${ }^{a}$ \\ Xia Yu, ${ }^{a}$ Feng-Ning Huan, ${ }^{a}$ Jing Lu, ${ }^{a}$ Dan Wang, ${ }^{c}$ Hong-Sheng Liu ${ }^{d}$ \\ and Chang-Lan Chen (D) *a
}

The trace element selenium has an insulin-like effect on humans and animals. In this study, the effect and mechanism of mouse selenoprotein $\mathrm{K}$ (mSelK) on the secretion of insulin from mouse MIN6 $\beta$ cells were investigated. An adenovirus vector, Ad-mSelK, was used to over-express the mSelK gene in the MIN6 $\beta$ cells. Likewise, a lentivirus vector, LV-mSelK-RNAi, was used to knockdown mSelK expression in the MIN6 $\beta$ cells. It was shown that the over-expression/knockdown of mSelK could increase/decrease the insulin secretion from MIN6 $\beta$ cells. Meanwhile, the cytosolic free $\mathrm{Ca}^{2+}$ level and inositol trisphosphate receptor type 3 (IP3R3) expression were also increased/decreased significantly as a consequence of the over-expression/knockdown of mSelK in MIN6 $\beta$ cells. Over-expression/knockdown of mSelK did not affect the expression of glutathione peroxidase 1 (GPX1) in the MIN6 $\beta$ cells. Further studies revealed that the mSelK expression and insulin release levels were increased significantly by treatment of MIN6 $\beta$ cells with selenium supplement (sodium selenite, $\mathrm{Na}_{2} \mathrm{SeO}_{3}$ ). In addition, mSelK protein levels were also upregulated significantly in MIN6 $\beta$ cells by adding glucose. These results suggest that mSelK plays a vital role in the process of trace element selenium promoting the secretion of insulin from MIN6 $\beta$ cells. The expression of mSelK may increase the secretion of insulin by improving the expression of IP3R3 on the endoplasmic reticulum (ER), which elevated the cytosolic free $\mathrm{Ca}^{2+}$ level by enhancing the release of $\mathrm{Ca}^{2+}$ from the ER.

Received 12th May 2017

Accepted 2nd July 2017

DOI: $10.1039 / \mathrm{c} 7 \mathrm{ra05379g}$

rsc.li/rsc-advances

\section{Introduction}

The trace element selenium (Se) has wide physiological effects: controlling the onset of human Kaschin-Beck disease and Keshan disease, boosting the innate immune system, maintaining thyroid function, preventing the occurrence of cardiovascular disease and Alzheimer's disease, increasing fertility, and preventing cancer etc. $^{\mathbf{1 , 2}}$ Most functions of selenium are implemented through selenoproteins. There are currently 25 known selenoproteins in the human proteome. ${ }^{3}$ Sixteen selenoproteins exist in the cytosol and exhibit antioxidative or other physiological effects. ${ }^{4}$ Nine mammalian selenoproteins are located in the endoplasmic reticulum (ER), including deiodinase 1, 2, and 3 (DIO1, DIO2, and DIO3), the $15 \mathrm{kDa}$ selenoprotein (Sep15), and selenoproteins $\mathrm{K}, \mathrm{M}, \mathrm{S}, \mathrm{N}$, and $\mathrm{T}^{2}$ They all have different physiological functions in cells.

${ }^{a}$ School of Pharmaceutical Science, Liaoning University, Shenyang 110036, China. E-mail: chenchanglanbio@aliyun.com; Fax: +86-024-62202469; Tel: +86-02462202192

${ }^{b}$ School of Life Science, Liaoning University, Shenyang 110036, China

${ }^{c}$ Research Center for Natural Product Pharmacy of Liaoning Province, Shenyang 110036, China

${ }^{d}$ Research Center for Computer Simulating and Information Processing of Biomacromolecules of Liaoning Province, Shenyang 110036, China
The insulin-like effect and the antidiabetic effect of Se have attracted increasing attention in recent years, although some researches proved that high level of selenium in humans and animals could increase the risk of type 2 diabetes (T2D). ${ }^{5-11}$ The influences of selenoproteins, such as glutathione peroxidase 1 (GPx1) and selenoprotein P (SePP), on the occurrence and development of T2D have been studied by many researchers. ${ }^{12-17}$ Among these studies, the surveys, which were reported that supplement of selenium increased the risk of T2D, were mostly obtained from the United States and other areas of the world in which the soils contain high selenium. ${ }^{18}$ However, in most parts of the world, soils are deficient in selenium., ${ }^{\mathbf{1 , 2}}$ Therefore, it is of great significance to moderately supply selenium for the prevention and treatment of T2D in these regions.

Studies have demonstrated that selenium could regulate insulin-mediated metabolism and exert insulin-like effect, and thus decrease the level of blood glucose. ${ }^{19-23}$ The mechanisms by which selenium reduces the risk of T2D were investigated from the relationship between selenoproteins and glucose metabolism. Selenoprotein M (SelM) was demonstrated to regulate the calcium signaling and prevent the oxidative stress in the islets cells. ${ }^{24}$ SelM deficiency in mice leads to adult-onset body to gain weight and increase adiposity, suggesting SelM has an important role in obesity. ${ }^{25}$ It has been shown that, in T2D 
patients, selenoprotein S (SelS) mRNA expression in subcutaneous adipose tissue is increased after insulin infusion, whereas no effect was seen in nondiabetic subjects. ${ }^{26}$ In addition, it was demonstrated that, in isolated human adipocytes, Sels expression is also up-regulated after insulin stimulation, which supports a role for SelS in the development of metabolic disease, especially in the context of insulin resistance. ${ }^{27}$ Selenoprotein $\mathrm{T}$ (SelT) was found to be up-regulated by pituitary adenylate cyclase-activating polypeptide (PACAP) in $\beta$-pancreatic cells, and it potentiated insulin secretion, which suggested that SelT may take part in glucose homeostasis. ${ }^{28}$ Conditional knockout of SelT in islet $\beta$ cells leads to defective insulin secretion, suggesting SelT is vital to the function of $\beta$ cells. However, the physiological functions of SelK in the secretion of insulin and the prevention of T2D are still unclear.

The increase of $\mathrm{Ca}^{2+}$ level in the cytoplasm can trigger insulin secretion from the $\beta$ cells. ${ }^{29-33}$ Insulin release and glucose homeostasis are closely associated with the subtle changes in calcium dynamics. ${ }^{34}$ Although the changes in calcium homeostasis play an important role in insulin secretion and insulin resistance, little is known about the relationship between the secretion of insulin and selenoproteins which can affect the intracellular $\mathrm{Ca}^{2+}$ level. In our previous studies, it was shown that selenoprotein SelK in Drosophila S2 cells and human gastric cancer BGC 823 cells could increase the expression of inositol trisphosphate receptor (IP3R) on the ER, which increased the level of intracellular free calcium by promoting the release of $\mathrm{Ca}^{2+}$ from ER to cytosol. ${ }^{35,36}$ And this effect has been verified by others. ${ }^{37,38}$ Further studies revealed that the stable expression of IP3R needs the palmitoylation of the protein, which requires the catalysis by an enzyme complex composed of DHHC6 (letters represent the amino acids aspartic acid, histidine, and cysteine in the catalytic domain) and selenoprotein SelK. The DHHC6/Selk interactions in the ER membrane depended on Src-homology 3 (SH3)/SH3 binding domain interactions of the two proteins. Therefore, an original DHHC6/SelK enzyme complex is vital for the regulation of stable expression level of IP3R. ${ }^{39}$

Thus, we consider that SelK may play an important role in the process which trace element selenium promotes islet $\beta$ cells to secrete insulin. In this paper, the influence of the overexpression/knockdown of mSelK on the insulin secretion from MIN6 $\beta$ cells was studied. And the mechanism of the above influence was explored by analyzing the variation of cytosolic $\mathrm{Ca}^{2+}$ level and IP3R expression in the cells after the overexpression/knockdown of mSelK. Moreover, the effect of selenium supplement (sodium selenite, $\mathrm{Na}_{2} \mathrm{SeO}_{3}$ ) on the expression of $\mathrm{mSelK}$ and the release of insulin was also investigated.

\section{Materials and methods}

\section{$2.1 \beta$ cells culture}

The mouse MIN6 $\beta$ cell line was a kind gift from Dr Qiu-Yu Wang (Liaoning University, Liaoning, China). The cells were cultured in Dulbecco's modified Eagle's medium (DMEM, Hyclone, Logan, UT, USA) containing $10 \%$ fetal bovine serum (FBS, Gibco, GrandIsland, NY, USA), penicillin (100 $\left.\mathrm{U} \mathrm{mL}^{-1}\right)$, streptomycin $\left(100 \mu \mathrm{g} \mathrm{mL} \mathrm{m}^{-1}\right), 0.5 \% \quad \beta$-mercaptoethanol, and $10 \mathrm{mM}$ L-glutamine at $37^{\circ} \mathrm{C}$ in a fully humidified incubator with $5 \% \mathrm{CO}_{2}$.

\subsection{Adenovirus vectors and adenovirus infection}

An adenovirus vector, Ad-mSelK, was used to over-express mSelK gene in the MIN6 $\beta$ cells. mSelK over-expression adenovirus vector (Ad-mSelK) and blank adenovirus vector (Ad) were constructed by HanBio Technology (Shanghai, China). MIN6 $\beta$ cells were seeded at $2 \times 10^{4}$ cells per well in 96well plates, or $1 \times 10^{6}$ cells per well in 6-well plates for $24 \mathrm{~h}$, and then treated with the above adenovirus vectors for $24 \mathrm{~h}$. The medium was then transferred to fresh medium without adenovirus vectors. After incubated for $24 \mathrm{~h}$, the infected $\beta$ cells were used for further experiments.

\subsection{Lentivirus vectors and lentivirus infection}

A lentivirus vector, LV-mSelK-RNAi, was used to knockdown the expression of mSelK gene in the MIN6 $\beta$ cells. mSelK knockdown lentivirus vector (LV-mSelK-RNAi) and blank lentivirus vector (LV) were constructed by GeneChem Company (Shanghai, China). MIN6 $\beta$ cells were seeded at $1 \times 10^{4}$ cells per well in 96-well plates, or $5 \times 10^{5}$ cells per well in 6 -well plates for $24 \mathrm{~h}$, and then treated with the above lentivirus vectors for $24 \mathrm{~h}$. The medium was then transferred to fresh medium without lentivirus vectors. After incubated for $48 \mathrm{~h}$, the infected $\beta$ cells were used for further experiments.

\subsection{Cell viability assay by MTT}

The cell viability was determined using the 3-(4,5dimethylthiazol-2-yl)-2,5-diphenyltetrazolium bromide (MTT, Gibco) assay. MIN6 $\beta$ cells treated with $\mathrm{Na}_{2} \mathrm{SeO}_{3}(0.1-300 \mu \mathrm{M})$ for $24 \mathrm{~h}$ were used to detect the cell viability. MIN6 $\beta$ cells were transfected with 2.5-20 multiplicity of infection (MOI) of the above vectors, and the cell viability was then evaluated by MTT assay. Briefly, the medium was removed and the cells were incubated with $0.25 \mathrm{mg} \mathrm{mL}{ }^{-1}$ MTT for $4 \mathrm{~h}$ at $37{ }^{\circ} \mathrm{C}$. The formazan crystals were dissolved in dimethyl sulfoxide (DMSO), and the absorbance was measured at $490 \mathrm{~nm}$ by a microplate reader (TECAN, Switzerland). Cell viability was expressed as the percentage values taking the non-infection control group (Con) as $100 \%$.

\subsection{Western blot analysis}

MIN6 $\beta$ cells transfected with the above vectors (15 MOI) were harvested to detect the expression of mSelK, GPx1, and IP3R3 proteins by western blot assay. MIN6 $\beta$ cells treated with $\mathrm{Na}_{2} \mathrm{SeO}_{3}(1-100 \mu \mathrm{M})$ or glucose $(2.5-25 \mathrm{mM})$ for $24 \mathrm{~h}$ were also used to test the expression of mSelK protein by western blot assay. Briefly, mouse MIN6 $\beta$ cells were lysed in ice-cold radio immunoprecipitation assay (RIPA) lysis buffer (Beyotime, Shanghai, China) supplemented with protease inhibitors $(1 \mathrm{mM}$ phenylmethyl-sulfonylfluoride, $1 \mu \mathrm{g} \mathrm{mL}{ }^{-1}$ pepstatin, $1 \mu \mathrm{g} \mathrm{mL}$ leupeptin, and $1 \mu \mathrm{g} \mathrm{mL} \mathrm{mL}^{-1}$ aprotinin) for $1 \mathrm{~h}$ at $4{ }^{\circ} \mathrm{C}$. And total proteins in the supernatant fluids were collected. Then proteins 
were boiled in loading buffer and separated on SDS-PAGE gels, followed by being transferred onto polyvinylidene fluoride membrane (PVDF, Millipore, Bedford, MA). After blocking, blots were incubated with primary antibodies against mouse mSelK (Sigma-Aldrich, St. Louis, MO, USA), GPx1 (Abcam, Cambridge, MA), IP3R3 (Santa Cruz, CA, USA), or mouse $\beta$-actin (Abcam), followed by being incubated with anti-rabbit (Sigma) or anti-goat (Santa Cruz) secondary antibodies. The membranes were processed with the enhanced chemiluminescence (ECL) reagents (Tanon, Shanghai, China) and visualized with a Tanon 5200 Multi Chemiluminescent System (Tanon).

\subsection{ELISA assay}

The enzyme-linked immunosorbent assay (ELISA) kit for mouse insulin was from Lvye Biotechnology (Jiangshu, China). ELISA was performed according to manufacturer's instructions. After the preparation of reagents, the diluted supernatant fluids of infected $\beta$ cells and non infected standard samples were added to the ELISA plate at $37^{\circ} \mathrm{C}$. After incubated for $30 \mathrm{~min}$, the plate was washed and added standard enzyme reagent for $30 \mathrm{~min}$ at $37{ }^{\circ} \mathrm{C}$. The plate was washed again and incubated in colored solution for $30 \mathrm{~min}$. After the addition of the stop solution, the absorbance was tested by the microplate reader.

\subsection{Measurement of cytosolic free $\mathrm{Ca}^{2+}$ level by flow cytometry}

MIN6 $\beta$ cells transfected with the above vectors (15 MOI) were harvested to detect the cytosolic $\mathrm{Ca}^{2+}$ level by loading the cells with Fluo-3/AM followed by flow cytometry analysis. The Fluo-3$\mathrm{Ca}^{2+}$ complex were able to give an increased green fluorescence with the excitation. Specific method was as follows: treated cells were digested using $0.25 \%$ trypsin, harvested by centrifugation, and washed thrice with ice-cold phosphate-buffered saline (PBS). Then the cells were re-suspended with $300 \mu \mathrm{L}$ DMEM medium without serum and antibiotic, subsequently, hatched with $5 \mu \mathrm{M}$ Fluo-3/AM for $30 \mathrm{~min}$ at $37^{\circ} \mathrm{C}$. After that, they were washed twice with PBS, re-suspended with $300 \mu \mathrm{L}$ of PBS, and immediately analyzed by a FACScan flow cytometer (BectonDickinson, San Jose, CA, USA).

\subsection{Real-time polymerase chain reaction (PCR) assay}

MIN6 $\beta$ cells transfected with the above vectors (15 MOI) were harvested to detect the mRNA expression of IP3 receptor type 1 , 2 , or 3 (IP3R1, IP3R2, or IP3R3) by real-time PCR. MIN6 $\beta$ cells treated with $\mathrm{Na}_{2} \mathrm{SeO}_{3}(10 \mu \mathrm{M})$ for $24 \mathrm{~h}$ were also used to detect the mRNA expression of mSelK by real-time PCR assay. Briefly, total RNA was extracted from MIN6 $\beta$ cells in TRIzol reagent (Invitrogen, Carlsbad, CA, USA) according to manufacturer's instructions. Total RNA $(1 \mu \mathrm{g})$ was reverse transcribed into complementary DNA (cDNA) in reaction volumes of $20 \mu \mathrm{L}$ using a PrimeScript ${ }^{\mathrm{TM}}$ RT reagent Kit with gDNA Eraser (TaKaRa, Japan). The cDNA was then analyzed by real-time PCR. Realtime PCR amplification was performed on a 7500 Fast RealTime PCR System (Applied Biosystems). Expression of genes was quantified by real-time PCR using a SYBR Premix Ex TaqTMII (TaKaRa) and $0.1 \mu \mathrm{g}$ of cDNA in each reaction. The following primers were used for amplification: mSelK forward, 5'-AAA AGA AAG AGG CTA CGG G-3'; mSelK reverse, 5' -TTA CCT TCC TCA TCC ACC-3 ${ }^{\prime}$; actin forward, $5^{\prime}$-TTC CTT CTT GGG TAT GGA AT-3'; actin reverse, 5'-GAG CAA TGA TCT TGA TCT TC-3'; IP3R1 forward, 5' ${ }^{\prime}$-AAG CGG ATG GAC CTG GTG TTA GAA CTG3'; IP3R1 reverse, $5^{\prime}$-AAT TTG TGC TGT GTG CTT CGC GTA GAA CT-3'; IP3R2 forward, 5'-CTG TTC TTC TTC ATC GTC ATC ATC ATC G-3'; IP3R2 reverse, 5'-GAA ACC AGT CCA AAT TCT TCT CCG TGA-3'; IP3R3 forward, $5^{\prime}$-CTT CTT TAT CGT CAT CAT CAT CGT GTT G-3'; IP3R3 reverse, 5'-AGG TTC TTG TTC TTG ATC ATC TGA GCC A-3'. For data analysis, the raw threshold cycle value of each sample was first normalized to that of actin. Thus, we calculated $\Delta C_{\mathrm{t}}$ for each sample and then the normalized $\Delta C_{\mathrm{t}}$. Ratio $=2^{-\Delta \Delta C_{\mathrm{t}}}$

\subsection{Statistical analysis}

SPSS 19.0 software was used to compare means by the Student's $t$-test between two groups or by one-way ANOVA among three or more groups. Data were represented as the means \pm SEM of three experiments.

\section{Results and discussion}

\subsection{Effect of mSelK on the insulin secretion from MIN6 $\beta$ cells}

Selenium has insulin-like effect. ${ }^{5-8}$ Most functions of selenium are implemented through selenoproteins. The influences of selenoproteins on the occurrence and development of T2D have been studied previously. ${ }^{22-28}$ However, the influence of selenoprotein SelK on T2D risk or insulin secretion has not been elucidated. In this study, the effect of SelK on insulin secretion in $\beta$ cells line was reported for the first time.

In order to eliminate the influence of the transfection of different vectors on the cell viability, the effect of various vectors on the viability of MIN6 $\beta$ cells was first detected by MTT method (Fig. 1A and B). After being transfected with above adenovirus vectors for $48 \mathrm{~h}$ or being transfected with above lentivirus vectors for $72 \mathrm{~h}$ in the concentration of 2.5-20 MOI, the viability of MIN6 $\beta$ cells had no significant change compared to the blank control group (Con). This suggested that the over-expression or knockdown of mSelK did not affect the viability of the $\beta$ cells.

The influence of the transfection of Ad vector (blank adenovirus vector), Ad-mSelK vector (mSelK over-expression adenovirus vector), LV vector (blank lentivirus vector), and LVmSelK-RNAi vector (mSelK knockdown lentivirus vector) on the expression of mSelK protein in the $\beta$ cells was detected by western blot assay (Fig. 1C and D). The results indicated that the expression of mSelK protein was increased in the $\beta$ cells transfected with Ad-mSelK vector (Fig. 1C), while the expression of mSelK was decreased by the transfection of LV-mSelK-RNAi vector compared to the blank control group (Fig. 1D). Moreover, the blank adenovirus vector (Ad) and blank lentivirus vector (LV) did not show significant influence on the mSelK protein (Fig. 1C and D). These results confirmed the efficiency 

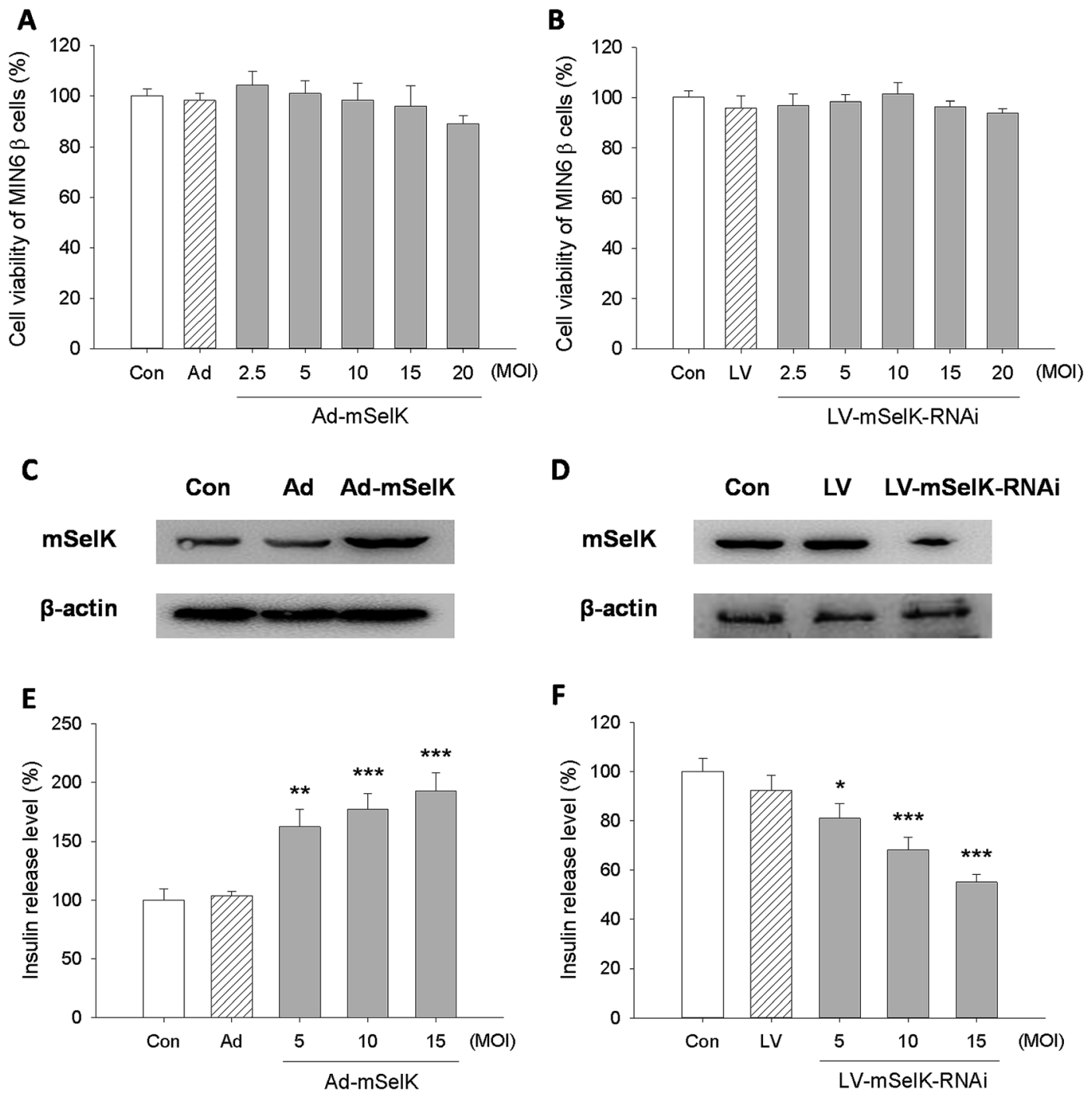

Fig. 1 Effect of mSelK on the insulin secretion from MIN6 $\beta$ cells. (A and B) Viability of $\beta$ cells transfected with the blank adenovirus vector (Ad), mSelK over-expression adenovirus vector (Ad-mSelK), blank lentivirus vector (LV), mSelK knockdown lentivirus vector (LV-mSelK-RNAi), or nontransfected cells (Con) was tested by MTT assay. ( $C$ and D) The expression of mSelK and $\beta$-actin protein in MIN6 $\beta$ cells transfected with Ad, AdmSelK, LV, LV-mSelK-RNAi, or non-transfected cells (Con) was analyzed by western blot. (E and F) Insulin release level of MIN6 $\beta$ cells transfected with with Ad, Ad-mSelK, LV, LV-mSelK-RNAi, or non-transfected cells (Con) was analyzed by ELISA. *P<0.05, **P<0.01,***P<0.001 as compared with the Con group.

of over-expression/knockdown of mSelK gene by transfecting cells with Ad-mSelK/LV-mSelK-RNAi vectors.

The influence of the over-expression/knockdown of mSelK on the release of insulin from the MIN6 $\beta$ cells was then tested by ELISA experiment. And it was shown that the level of insulin released from MIN6 $\beta$ cells transfected with Ad-mSelK vector was significantly elevated compared to the control group (Con) in a MOI-dependent manner (Fig. 1E). In contrast, insulin level released from the $\beta$ cells transfected with LV-mSelK-RNAi was declined significantly, and also in a MOI-dependent manner (Fig. 1F). The Ad and LV groups did not show significant variation (Fig. 1E and F). These data strongly suggested that the release of insulin is closely related to the expression of mSelK in MIN6 $\beta$ cells.

Since the increased insulin level in islet $\beta$ cells was associated with the elevated level of selenoprotein GPx1, an antioxidant enzyme existed in cytosol, ${ }^{\mathbf{1 2 , 4 0 - 4 2}}$ the influence of the over-expression/knockdown of mSelK on the expression of GPx1 in the MIN6 $\beta$ cells was investigated. The result showed that the expression of GPx1 was not altered in the transfected cells, indicating that over-expression/knockdown of mSelK did not affect the GPx1 in the MIN6 $\beta$ cells (data not shown).

\subsection{Effect of mSelK on the intracellular free $\mathrm{Ca}^{2+}$ level in MIN6 $\beta$ cells}

Glucose and other nutrients promote islet $\beta$ cells to release insulin by increasing intracellular ATP/ADP ratio, resulting in the closure of the $\mathrm{K}_{\mathrm{ATP}}$ channel, cell membrane depolarization, and calcium influx. The increase of $\mathrm{Ca}^{2+}$ level in the cytoplasm can trigger insulin secretion. ${ }^{29-33}$ In our previous studies, it is 
shown that selenoprotein SelK in Drosophila S2 cells and human gastric cancer BGC 823 cells can increase the level of cytosolic free $\mathrm{Ca}^{2+}$ by promoting the release of $\mathrm{Ca}^{2+}$ from the ER to cytosol. ${ }^{35,36}$ In order to illustrate the inherent mechanism of the increased insulin secretion, the influence of the overexpression and knockdown of $\mathrm{mSelK}$ on the cytosolic free $\mathrm{Ca}^{2+}$ level in MIN6 $\beta$ cells was also investigated. It was shown by flow cytometry that cytosolic free $\mathrm{Ca}^{2+}$ level was elevated by the over-expression of mSelK and declined by the knockdown of mSelK in MIN6 $\beta$ cells compared to the control group (Con) (Fig. 2A and B), just like the results in Drosophila S2 cell line and human gastric cancer BGC 823 cell line by our group ${ }^{35,36}$ and in T cells, neutrophils, and macrophages by Verma et al. ${ }^{37}$ And it was shown that after the over-expression/knockdown of mSelK, the intracellular free $\mathrm{Ca}^{2+}$ level was increased/ decreased to $149 \% / 70 \%$ compared to the blank control group (taking blank control group as $100 \%$ ), which suggested that the variation of free $\mathrm{Ca}^{2+}$ level in MIN6 $\beta$ cells by the overexpression/knockdown of mSelK was similar to that of the release of insulin.

\subsection{Effect of mSelK on the IP3R expression level in MIN6 $\beta$ cells}

The basic molecular function of SelK is increasing the stable expression of IP3R by catalyzing the palmitoylation of IP3R. ${ }^{38}$ The increased expression of IP3R by the SelK up-regulation stimulates the release of $\mathrm{Ca}^{2+}$ from the ER calcium store to the cytosol of the cells. ${ }^{35,36}$ IP3R is a ligand-gated ion channel protein presented on ER and nuclear envelope, which was originally identified in mouse pancreas cells. IP3R is classified in five types, among which IP3R types 1, 2, and 3 (IP3R1, IP3R2, and IP3R3) are expressed in islet $\beta$ cells and IP3R3 is the most abundant in this gland. ${ }^{33}$

In this study, the effect of mSelK on the mRNA transcription of IP3R1, IP3R2, or IP3R3 in MIN6 $\beta$ cells was investigated by real-time PCR. As shown in Fig. 3A-C, in mSelK knockdown cells, the mRNA expression of IP3R1 and IP3R2 had no significant change, while the mRNA level of IP3R3 decreased significantly. On the other hand, as shown in Fig. 3D-F, the mRNA expression of IP3R1 and IP3R2 in mSelK over-expressed cells also had no significant change, while the IP3R3 mRNA level was
A
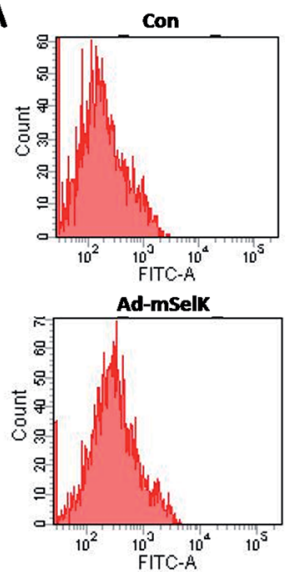

B
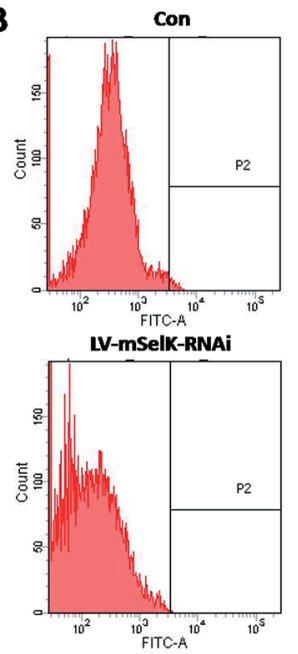
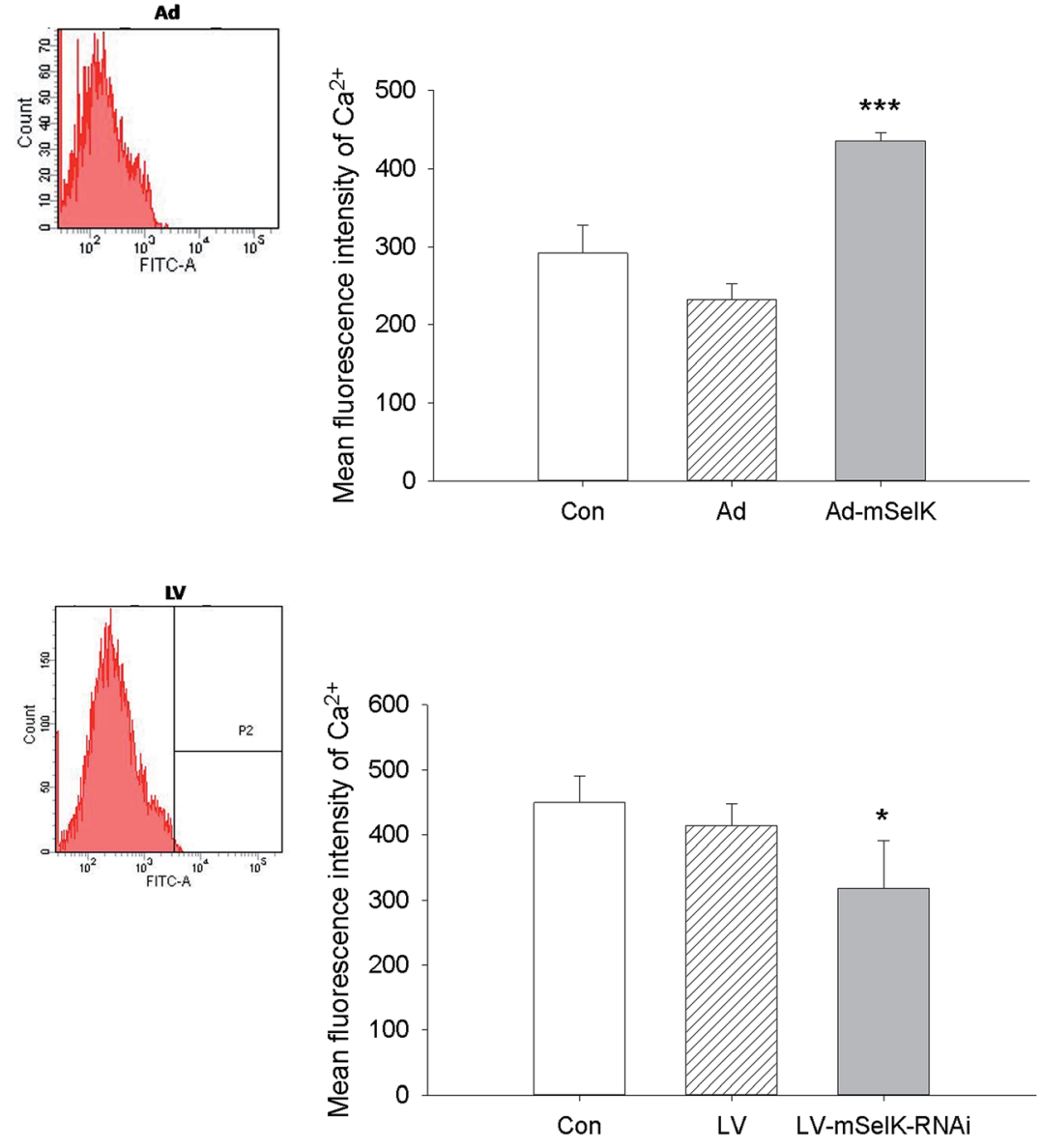

Fig. 2 Effect of mSelK on the intracellular free $\mathrm{Ca}^{2+}$ level in MIN6 $\beta$ cells. (A) The cytosolic free $\mathrm{Ca}^{2+}$ level in the $\beta$ cells transfected with Ad, AdmSelK, or non-transfected cells (Con). (B) The cytosolic free $\mathrm{Ca}^{2+}$ level in the $\beta$ cells transfected with LV, LV-mSelK-RNAi, or non-transfected cells (Con). The intracellular free $\mathrm{Ca}^{2+}$ levels were detected by flow cytometry after the cells were loaded with Fluo-3/AM. $* P<0.05, * * * P<0.001$ as compared with the Con group. 
A

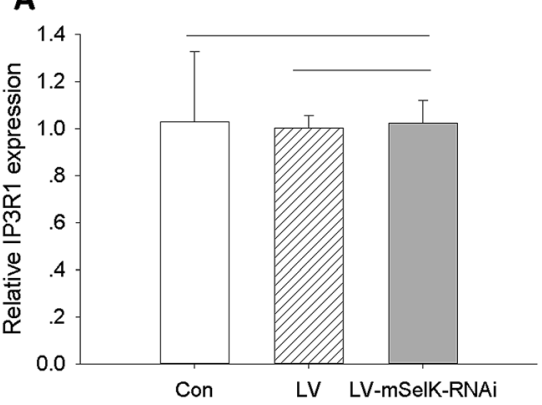

D

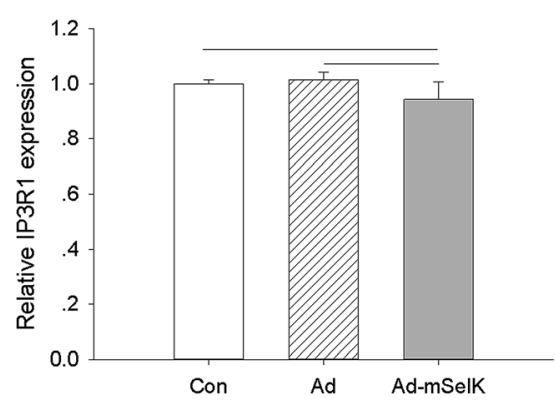

G

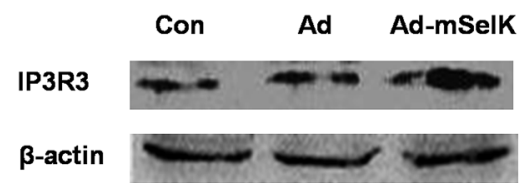

B

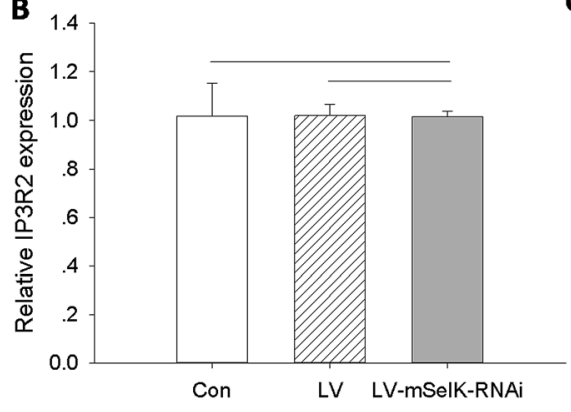

E

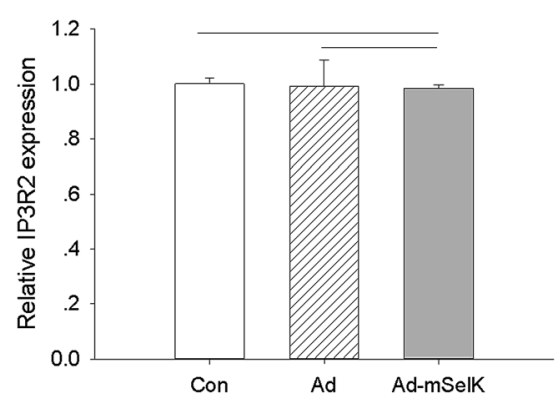

C

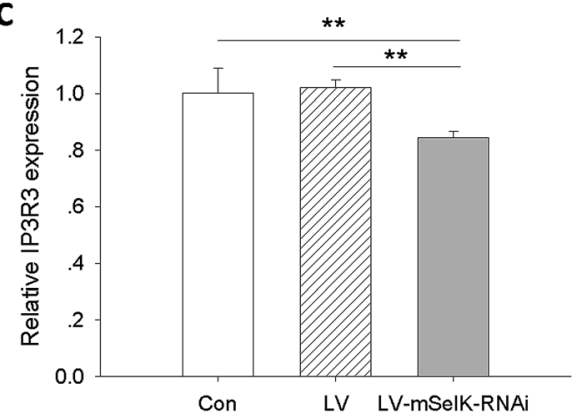

F

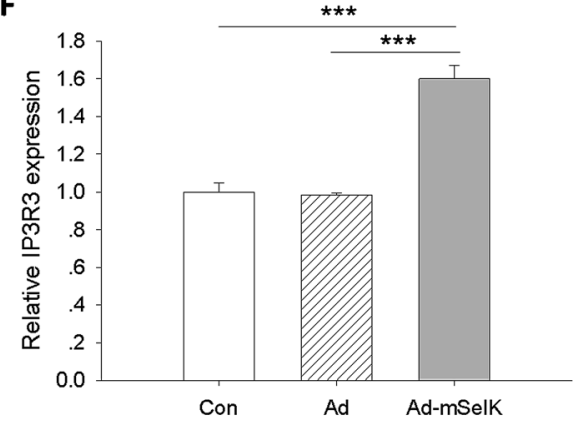

Fig. 3 Effect of mSelK on the IP3R expression level in MIN6 $\beta$ cells. Transcript levels of IP3R1 (A), IP3R2 (B), and IP3R3 (C) in MIN6 $\beta$ cells transfected with LV, LV-mSelK-RNAi, or non-transfected cells (Con) were assessed by real-time PCR. Transcript levels of IP3R1 (D), IP3R2 (E), and IP3R3 (F) in MIN6 $\beta$ cells transfected with Ad, Ad-mSelK, or non-transfected cells (Con) was assessed by real-time PCR. ** $P<0.01, * * * P<0.001$. (G) The expression of IP3R3 and $\beta$-actin protein in MIN6 $\beta$ cells transfected with Ad, Ad-mSelK, or non-transfected cells (Con) was analyzed by western blot.

increased significantly. Since only the transcript level of IP3R3 was significantly influenced by the over-expression/knockdown of mSelK, the expression level of IP3R3 protein was detected by western blot, and it was shown that the expression of IP3R3 protein was also significantly increased in mSelK over-expressed MIN6 $\beta$ cells (Fig. 3G). SelK has been demonstrated to increase the expression of IP3R in macrophage, BGC823, and other mammalian cells..$^{35,36,43}$ This is the first report for the potent enhancement effect of mSelK on the expression of IP3R3 in the $\beta$ cells. These data strongly suggest that the expression of mSelK up-regulates IP3R3 mRNA transcription followed by increasing IP3R3 protein production in MIN6 $\beta$ cells. Thus, our results presented here indicated that mSelK may acts to enhance the insulin secretion from MIN6 $\beta$ cells by increasing the cytosolic free $\mathrm{Ca}^{2+}$ level resulted from the up-regulated IP3R3 expression. The stable expression of IP3R needs the palmitoylation of the protein, which requires the catalysis of an enzyme complex composed of DHHC6 and SelK on the ER membrane. ${ }^{39}$ Therefore, an original DHHC6/ SelK enzyme complex is vital for the regulation of stable expression level of the IP3R. Further studies are required in order to understand whether mSelK acts to regulate the IP3R3 expression by the palmitoylation of the protein in MIN6 $\beta$ cells.

\subsection{Effect of trace element selenium on the expression of mSelK and the release of insulin}

Studies have demonstrated that trace element selenium has insulin-like effect, and moderate selenium supplements can reduce the T2D risk. ${ }^{5,19,20}$ Although the increased expression of SelK by selenium supplements has been studied in hepatocarcinoma cell, ${ }^{44}$ lung cancer cells, prostate cancer cells, colon cancer cells, ${ }^{45}$ and muscle cells, ${ }^{46}$ the influence of selenium supplements on the expression of SelK in islet $\beta$ cells has not been studied. In this study, after treatment of mouse MIN6 $\beta$ cells with different concentrations of $\mathrm{Na}_{2} \mathrm{SeO}_{3}$ in vitro for $24 \mathrm{~h}$, the expression of mSelK was assessed by real-time PCR and western blot, and the release level of insulin was measured by ELISA.

According to the result of cytotoxicity test, treatment of MIN6 $\beta$ cells with $\mathrm{Na}_{2} \mathrm{SeO}_{3}(0.1-10 \mu \mathrm{M})$ did not affect the cell viability. The toxicity was found when the cells were treated with $\mathrm{Na}_{2} \mathrm{SeO}_{3}$ at the concentration of 30-300 $\mu \mathrm{M}$ (Fig. 4A).

The result of real-time PCR analysis showed that the mSelK mRNA expression is increased in the presence of $\mathrm{Na}_{2} \mathrm{SeO}_{3}(10$ $\mu \mathrm{M})$. The relative mSelK mRNA expression efficiency of $\mathrm{Na}_{2} \mathrm{SeO}_{3}$ treated group was $226 \pm 8 \%$ (Fig. 4C). Further studies by 
A

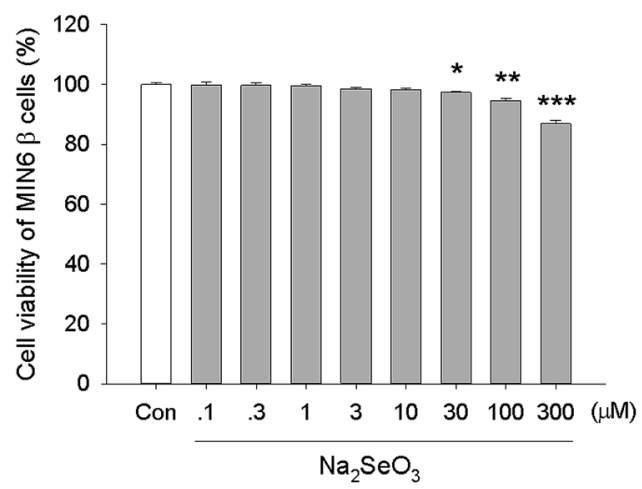

C

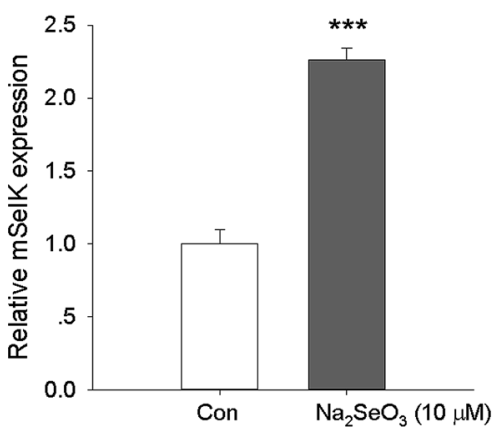

B

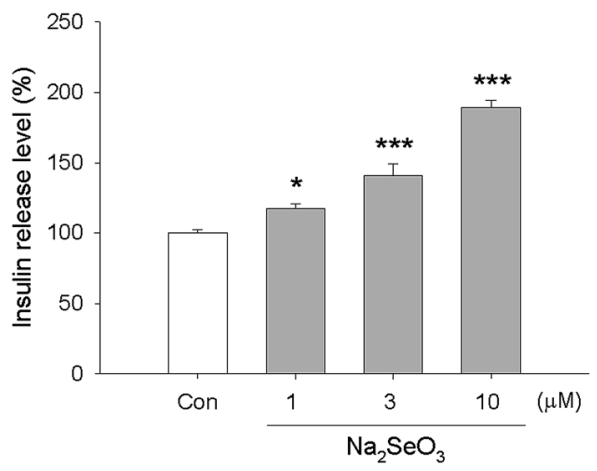

D

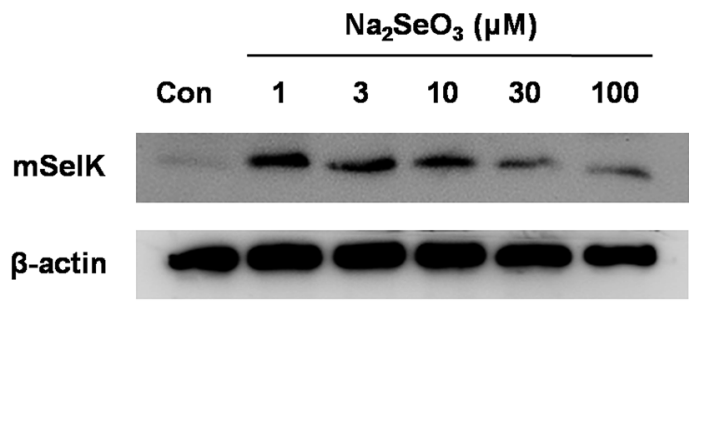

Fig. 4 Effect of trace element selenium on the expression of mSelK and the release of insulin. (A) Viability of MIN6 $\beta$ cells treated with $\mathrm{Na}_{2} \mathrm{SeO} 3$ $(0.1-300 \mu \mathrm{M})$ for $24 \mathrm{~h}$ was tested by MTT assay. (B) Insulin release level of MIN6 $\beta$ cells treated with $\mathrm{Na}_{2} \mathrm{SeO}_{3}(1-10 \mu \mathrm{M})$ for $24 \mathrm{~h}$ was analyzed by ELISA. (C) Transcript level of mSelK in MIN6 $\beta$ cells treated with $\mathrm{Na}_{2} \mathrm{SeO}_{3}(10 \mu \mathrm{M})$ for $24 \mathrm{~h}$ was assessed by real-time PCR. (D) The expression of mSelK and $\beta$-actin protein in MIN6 $\beta$ cells treated with $\mathrm{Na}_{2} \mathrm{SeO}_{3}(1-100 \mu \mathrm{M})$ for $24 \mathrm{~h}$ was assayed by western blot. *P<0.05, **P<0.01, **** $<$ 0.001 as compared with the Con group.

western blot showed that the levels of mSelK protein in MIN6 $\beta$ cells was markedly up-regulated after $\mathrm{Na}_{2} \mathrm{SeO}_{3}(1-100 \mu \mathrm{M})$ treatment for $24 \mathrm{~h}$. The effects of $\mathrm{Na}_{2} \mathrm{SeO}_{3}$ on the expression of SelK in human hepatoma cell lines (HepG2, Huh7 and HCC) had been assessed previously in vitro, and the results showed that the increase observed for the SelK expression is correlated with the increase of $\mathrm{Na}_{2} \mathrm{SeO}_{3}{ }^{47,48}$ The results obtained here in MIN6 $\beta$ cells are consistent with those reports. ${ }^{47,48}$ Moreover, when the cells were treated with excess amounts of $\mathrm{Na}_{2} \mathrm{SeO}_{3}(30$ and $100 \mu \mathrm{M}$ ), the mSelK expression levels were decreased obviously compared to the $\mathrm{Na}_{2} \mathrm{SeO}_{3}(1-10 \mu \mathrm{M})$ groups (Fig. 4D). One of the reasons for this phenomenon could be that excessive $\mathrm{Na}_{2} \mathrm{SeO}_{3}$ (30 and $100 \mu \mathrm{M}$ ) might induce oxidative stress and lesions of ER membrane, resulting in declined mSelK expression on the ER of cells.

As shown in Fig. 4B, $\mathrm{Na}_{2} \mathrm{SeO}_{3}(1,3$, and $10 \mu \mathrm{M})$ could significantly increase the insulin release level in a concentration-dependent manner, which was consistent with the previous report. $^{49}$

These data indicated that $\mathrm{Na}_{2} \mathrm{SeO}_{3}$ could increase the expression of mSelK and the release of insulin in MIN6 $\beta$ cells. Our results revealed that $\mathrm{mSelK}$ may be an important selenoprotein for trace element selenium exerting their potential roles in the prevention and treatment of $\mathrm{T} 2 \mathrm{D}$ by triggering the insulin secretion from islet $\beta$ cells.

\subsection{Effect of glucose on the expression of mSelK in MIN6 $\beta$ cells}

It is well known that the insulin secretion from islet $\beta$ cells can be increased by glucose supply. ${ }^{50,51}$ Glucose administration revealed that SelT-knockout mice display impaired glucose tolerance, which showed that SelT is involved in the control of glucose homeostasis. ${ }^{28}$ SePP levels were decreased in isolated murine islets cultured in high-glucose medium, which might contribute to glucotoxicity in islets $\beta$ cells. ${ }^{52}$ Moreover, serum Sels levels have been demonstrated to be negatively correlated with fasting plasma glucose. ${ }^{53}$ However, the effect of glucose on the expression of SelK is still unclear.

In order to test the effect of glucose on mSelK expression in the $\beta$ cells, mouse MIN6 $\beta$ cells were treated with low glucose (2.8 $\mathrm{mM})$, normal glucose $(5.6 \mathrm{mM}$, the glucose concentration in the DMEM medium applied for MIN6 cell culture), or high glucose

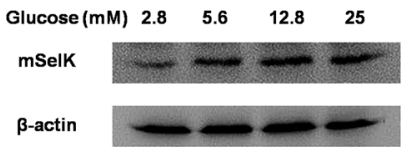

Fig. 5 Effect of glucose on the expression of mSelK in MIN6 $\beta$ cells. Expression of $\mathrm{mSelK}$ and $\beta$-actin protein in MIN6 $\beta$ cells treated with glucose $(2.5-25 \mathrm{mM})$ for $24 \mathrm{~h}$ was assayed by western blot. 
(12.8 and $25 \mathrm{mM}$ ) for $24 \mathrm{~h}$, and the expression of mSelK protein was assessed by western blot. The result showed that mSelK expression is obviously increased by glucose supply (Fig. 5). This suggested that, in MIN6 $\beta$ cells, mSelK expression and insulin release might have a close association. mSelK may act as a regulator in the process of glucose regulating insulin secretion from MIN6 $\beta$ cells. Further studies are required to clarify the role of mSelK in the prevention and/or treatment of diabetes.

\section{Conclusion}

In summary, our data indicate a novel role of SelK in insulin secretion of MIN6 $\beta$ cells. It is demonstrated that mSelK acts to enhance the secretion of insulin from MIN6 $\beta$ cells by increasing the cytosolic free $\mathrm{Ca}^{2+}$ level resulted from the upregulated IP3R3 expression, and mSelK plays a vital role in the process of trace element selenium promoting the insulin secretion. These results suggest that mSelK may be an important selenoprotein for selenium exerting their functions in the prevention and/or treatment of T2D by enhancing the insulin secretion from islet $\beta$ cells.

\section{Acknowledgements}

The authors are grateful to Dr Qiu-Yu Wang (Liaoning University, Liaoning, China) for providing mouse MIN6 $\beta$ cells and Dr Hao Pan (Liaoning University, Liaoning, China) for the review and editing of the manuscript. This study was supported by the National Natural Science Foundation of China (No. 31371085 and No. 81503085), the Foundation of the Education Department of Liaoning Province of China (No. L2013010 and No. LT2015011), and the Foundation of the Department of Science and Technology of Liaoning Province of China (No. 2014020171).

\section{References}

1 C. Chen, F. Huan, X. Meng and J. Lv, The effect of selenium on human health and diseases and the scientifically supplementation of selenium to human bodies, J. Liaoning Univ., Nat. Sci. Ed., 2016, 45, 155-168.

2 M. P. Rayman, Selenium and human health, Lancet, 2012, 379, 1256-1268.

3 G. V. Kryukov, S. Castellano, S. V. Novoselov, A. V. Lobanov, O. Zehtab, R. Guigó and V. N. Gladyshev, Characterization of mammalian selenoproteomes, Science, 2003, 300, 14391443.

4 R. Pillai, J. H. Uyehara-Lock and F. P. Bellinger, Selenium and selenoprotein function in brain disorders, IUBMB Life, 2014, 66, 229-239.

5 O. Bozkurt, S. Haman Bayari, M. Severcan, C. Krafft, J. Popp and F. Severcan, Structural alterations in rat liver proteins due to streptozotocin-induced diabetes and the recovery effect of selenium: Fourier transform infrared microspectroscopy and neural network study, J. Biomed. Opt., 2012, 17, 076023.
6 X. Q. Sheng, K. X. Huang and H. B. Xu, New experimental observation on the relationship of selenium and diabetes mellitus, Biol. Trace Elem. Res., 2004, 99, 241-253.

7 S. Roy, S. K. Dontamalla, A. K. Mondru, S. Sannigrahi and P. R. Veerareddy, Downregulation of apoptosis and modulation of TGF- $\beta 1$ by sodium selenate prevents streptozotocin-induced diabetic rat renal impairment, Biol. Trace Elem. Res., 2011, 139, 55-71.

8 J. Zhou, K. Huang and X. G. Lei, Selenium and diabetesevidence from animal studies, Free Radical Biol. Med., 2013, 65, 1548-1556.

9 P. Faure, O. Ramon, A. Favier and S. Halimi, Selenium supplementation decreases nuclear factor-kappa B activity in peripheral blood mononuclear cells from type 2 diabetic patients, Eur. J. Clin. Invest., 2004, 34, 475-481.

10 S. S. Pillai, J. K. Sugathan and M. Indira, Selenium downregulates RAGE and $\mathrm{NF} \kappa \mathrm{B}$ expression in diabetic rats, Biol. Trace Elem. Res., 2012, 149, 71-77.

11 G. M. Barakat, M. E. Moustafa and A. B. Bikhazi, Effects of selenium and exendin-4 on glucagon-like peptide-1 receptor, IRS-1, and Raf-1 in the liver of diabetic rats, Biochem. Genet., 2012, 50, 922-935.

12 J. P. McClung, C. A. Roneker, W. Mu, D. J. Lisk, P. Langlais, F. Liu and X. G. Lei, Development of insulin resistance and obesity in mice overexpressing cellular glutathione peroxidase, Proc. Natl. Acad. Sci. U. S. A., 2004, 101, 88528857.

13 X. Chen, T. O. Scholl, M. J. Leskiw, M. R. Donaldson and T. P. Stein, Association of glutathione peroxidase activity with insulin resistance and dietary fat intake during normal pregnancy, J. Clin. Endocrinol. Metab., 2003, 88, 5963-5968.

14 H. Steinbrenner, B. Speckmann, A. Pinto and H. Sies, High selenium intake and increased diabetes risk: experimental evidence for interplay between selenium and carbohydrate metabolism, J. Clin. Biochem. Nutr., 2011, 48, 40-45.

15 L. Schomburg and J. Köhrle, On the importance of selenium and iodine metabolism for thyroid hormone biosynthesis and human health, Mol. Nutr. Food Res., 2008, 52, 12351246.

16 H. Misu, T. Takamura, H. Takayama, H. Hayashi, N. Matsuzawa-Nagata, S. Kurita, K. Ishikura, H. Ando, Y. Takeshita, T. Ota, M. Sakurai, T. Yamashita, E. Mizukoshi, T. Yamashita, M. Honda, K. Miyamoto, T. Kubota, N. Kubota, T. Kadowaki, H. J. Kim, I. K. Lee, Y. Minokoshi, Y. Saito, K. Takahashi, Y. Yamada, N. Takakura and S. Kaneko, A liver-derived secretory protein, selenoprotein $\mathrm{P}$, causes insulin resistance, Cell Metab., 2010, 12, 483-495.

17 S. J. Yang, S. Y. Hwang, H. Y. Choi, H. J. Yoo, J. A. Seo, S. G. Kim, N. H. Kim, S. H. Baik, D. S. Choi and K. M. Choi, Serum selenoprotein P levels in patients with type 2 diabetes and prediabetes: implications for insulin resistance, inflammation, and atherosclerosis, J. Clin. Endocrinol. Metab., 2011, 96, E1325-E1329.

18 S. Stranges, J. R. Marshall, R. Natarajan, R. P. Donahue, M. Trevisan, G. F. Combs, F. P. Cappuccio, A. Ceriello and 
M. E. Reid, Effects of long-term selenium supplementation on the incidence of type 2 diabetes: a randomized trial, Ann. Intern. Med., 2007, 147, 217-223.

19 D. Hwang, S. Seo, Y. Kim, C. Kim, S. Shim, S. Jee, S. Lee, M. Jang, M. Kim, S. Yim, S. K. Lee, B. Kang, I. Jang and J. Cho, Selenium acts as an insulin-like molecule for the down-regulation of diabetic symptoms via endoplasmic reticulum stress and insulin signalling proteins in diabetes-induced non-obese diabetic mice, J. Biosci., 2007, 32, 723-735.

20 Y. J. Hei, S. Farahbakhshian, X. Chen, M. L. Battell and J. H. McNeill, Stimulation of MAP kinase and S6 kinase by vanadium and selenium in rat adipocytes, Mol. Cell. Biochem., 1998, 178, 367-375.

21 A. Pinto, B. Speckmann, M. Heisler, H. Sies and H. Steinbrenner, Delaying of insulin signal transduction in skeletal muscle cells by selenium compounds, J. Inorg. Biochem., 2011, 105, 812-820.

22 A. Pinto, D. T. Juniper, M. Sanil, L. Morgan, L. Clark, H. Sies, M. P. Rayman and H. Steinbrenner, Supranutritional selenium induces alterations in molecular targets related to energy metabolism in skeletal muscle and visceral adipose tissue of pigs, J. Inorg. Biochem., 2012, 114, 47-54.

23 S. S. Kim, J. H. Koo, I. S. Kwon, Y. S. Oh, S. J. Lee, E. J. Kim, W. K. Kim, J. Lee and J. Y. Cho, Exercise training and selenium or a combined treatment ameliorates aberrant expression of glucose and lactate metabolic proteins in skeletal muscle in a rodent model of diabetes, Nutr. Res. Pract., 2011, 5, 205-213.

24 L. Ozcan, A. S. Ergin, A. Lu, J. Chung, S. Sarkar, D. Nie, M. G. Myers Jr and U. Ozcan, Endoplasmic reticulum stress plays a central role in development of leptin resistance, Cell Metab., 2009, 9, 35-51.

25 M. A. Reeves, F. P. Bellinger and M. J. Berry, The neuroprotective functions of selenoprotein $\mathbf{M}$ and its role in cytosolic calcium regulation, Antioxid. Redox Signaling, 2010, 12, 809-818.

26 H. K. Karlsson, H. Tsuchida, S. Lake, H. A. Koistinen and A. Krook, Relationship between serum amyloid A level and Tanis/SelS mRNA expression in skeletal muscle and adipose tissue from healthy and type 2 diabetic subjects, Diabetes, 2004, 53, 1424-1428.

27 M. Olsson, B. Olsson, P. Jacobson, D. S. Thelle, J. Björkegren, A. Walley, P. Froguel, L. M. Carlsson and K. Sjöholm, Expression of the selenoprotein $S$ (SELS) gene in subcutaneous adipose tissue and SELS genotype are associated with metabolic risk factors, Metabolism, 2011, 60, 114-120.

28 G. Prevost, A. Arabo, L. Jian, E. Quelennec, D. Cartier, S. Hassan, A. Falluel-Morel, Y. Tanguy, S. Gargani, I. Lihrmann, J. Kerr-Conte, H. Lefebvre, F. Pattou and Y. Anouar, The PACAP-regulated gene selenoprotein $\mathrm{T}$ is abundantly expressed in mouse and human $\beta$-cells and its targeted inactivation impairs glucose tolerance, Endocrinology, 2013, 154, 3796-3806.

29 P. Thams, M. R. Anwar and K. Capito, Glucose triggers protein kinase A-dependent insulin secretion in mouse pancreatic islets through activation of the $\mathrm{K}_{\mathrm{ATP}}{ }^{+}$channeldependent pathway, Eur. J. Endocrinol., 2005, 152, 671-677.

30 H. Hatakeyama, T. Kishimoto, T. Nemoto, H. Kasai and N. Takahashi, Rapid glucose sensing by protein kinase A for insulin exocytosis in mouse pancreatic islets, J. Physiol., 2006, 570, 271-282.

31 S. G. Straub and G. W. Sharp, Glucose-stimulated signaling pathways in biphasic insulin secretion, Diabetes/Metab. Res. Rev., 2002, 18, 451-463.

$32 \mathrm{X}$. Zhou, W. Yang and J. Li, $\mathrm{Ca}^{2+}$ - and protein kinase Cdependent signaling pathway for nuclear factor-kappa $\mathrm{B}$ activation, inducible nitric-oxide synthase expression, and tumor necrosis factor-alpha production in lipopolysaccharide-stimulated rat peritoneal macrophages, J. Biol. Chem., 2006, 281, 31337-31347.

33 O. Blondel, J. Takeda, H. Janssen, S. Seino and G. I. Bell, Sequence and functional characterization of a third inositol trisphosphate receptor subtype, IP3R-3, expressed in pancreatic islets, kidney, gastrointestinal tract, and other tissues, J. Biol. Chem., 1993, 268, 11356-11363.

34 L. Li, A. Trifunovic, M. Köhler, Y. Wang, J. Petrovic Berglund, C. Illies, L. Juntti-Berggren, N. G. Larsson and P. O. Berggren, Defects in $\beta$-cell $\mathrm{Ca}^{2+}$ dynamics in age-induced diabetes, Diabetes, 2014, 63, 4100-4114.

35 S. B. Ben, Q. Y. Wang, L. Xia, J. Z. Xia, J. Cui, J. Wang, F. Yang, H. Bai, M. S. Shim, B. J. Lee, L. G. Sun and C. L. Chen, Selenoprotein dSelK in Drosophila elevates release of $\mathrm{Ca}^{2+}$ from endoplasmic reticulum by upregulating expression of inositol 1,4,5-tris-phosphate receptor, Biochemistry, 2011, 76, 1030-1036.

36 S. B. Ben, B. Peng, G. C. Wang, C. Li, H. F. Gu, H. Jiang, X. L. Meng, B. J. Lee and C. L. Chen, Overexpression of selenoprotein SelK in BGC-823 cells inhibits cell adhesion and migration, Biochemistry, 2015, 80, 1344-1353.

37 S. Verma, F. W. Hoffmann, M. Kumar, Z. Huang, K. Roe, E. Nguyen-Wu, A. S. Hashimoto and P. R. Hoffmann, Selenoprotein $\mathrm{K}$ knockout mice exhibit deficient calcium flux in immune cells and impaired immune responses, $J$. Immunol., 2011, 186, 2127-2137.

38 Z. Huang, F. W. Hoffmann, R. L. Norton, A. C. Hashimoto and P. R. Hoffmann, Selenoprotein $\mathrm{K}$ is a novel target of $\mathrm{m}$-calpain, and cleavage is regulated by Toll-like receptorinduced calpastatin in macrophages, J. Biol. Chem., 2011, 286, 34830-34838.

39 G. J. Fredericks, F. W. Hoffmann, A. H. Rose, H. J. Osterheld, F. M. Hess, F. Mercier and P. R. Hoffmann, Stable expression and function of the inositol 1,4,5-triphosphate receptor requires palmitoylation by a DHHC6/selenoprotein $\mathrm{K}$ complex, Proc. Natl. Acad. Sci. U. S. A., 2014, 111, 1647816483.

40 X. D. Wang, M. Z. Vatamaniuk, S. K. Wang, C. A. Roneker, R. A. Simmons and X. G. Lei, Molecular mechanisms for hyperinsulinaemia induced by overproduction of seleniumdependent glutathione peroxidase-1 in mice, Diabetologia, 2008, 51, 1515-1524.

$41 \mathrm{X}$. Yang, L. Feng, C. Li and Y. Li, Tranilast alleviates endothelial dysfunctions and insulin resistance via 
preserving glutathione peroxidase 1 in rats fed a high-fat emulsion, J. Pharmacol. Sci., 2014, 124, 18-30.

42 T. L. Merry, M. Tran, M. Stathopoulos, F. Wiede, B. C. Fam, G. T. Dodd, I. Clarke, M. J. Watt, S. Andrikopoulos and T. Tiganis, High-fat-fed obese glutathione peroxidase 1deficient mice exhibit defective insulin secretion but protection from hepatic steatosis and liver damage, Antioxid. Redox Signaling, 2014, 20, 2114-2129.

43 V. A. Shchedrina, R. A. Everley, Y. Zhang, S. P. Gygi, D. L. Hatfield and V. N. Gladyshev, Selenoprotein K binds multiprotein complexes and is involved in the regulation of endoplasmic reticulum homeostasis, J. Biol. Chem., 2011, 286, 42937-42948.

44 F. Rusolo, B. Pucci, G. Colonna, F. Capone, E. Guerriero, M. R. Milone, M. Nazzaro, M. G. Volpe, G. Di Bernardo, G. Castello and S. Costantini, Evaluation of selenite effects on selenoproteins and cytokinome in human hepatoma cell lines, Molecules, 2013, 18, 2549-2562.

45 L. H. Sun, J. G. Li, H. Zhao, J. Shi, J. Q. Huang, K. N. Wang, X. J. Xia, L. Li and X. G. Lei, Porcine serum can be biofortified with selenium to inhibit proliferation of three types of human cancer cells, J. Nutr., 2013, 143, 1115-1122.

46 H. Yao, W. Zhao, X. Zhao, R. Fan, P. A. Khoso, Z. Zhang, $\mathrm{W}$. Liu and $\mathrm{S}$. Xu, Selenium deficiency mainly influences the gene expressions of antioxidative selenoproteins in chicken muscles, Biol. Trace Elem. Res., 2014, 161, 318-327.

47 F. Rusolo, B. Pucci, G. Colonna, F. Capone, E. Guerriero, M. R. Milone, M. Nazzaro, M. G. Volpe, G. Di Bernardo,
G. Castello and S. Costantini, Evaluation of selenite effects on selenoproteins and cytokinome in human hepatoma cell lines, Molecules, 2013, 18, 2549-2562.

48 N. Potenza, F. Castiello, M. Panella, G. Colonna, G. Ciliberto, A. Russo and S. Costantini, Human MiR-544a Modulates SELK Expression in Hepatocarcinoma Cell Lines, PLoS One, 2016, 11, e0156908.

49 S. C. Campbell, A. Aldibbiat, C. E. Marriott, C. Landy, T. Ali, W. F. Ferris, C. S. Butler, J. A. Shaw and W. M. Macfarlane, Selenium stimulates pancreatic beta-cell gene expression and enhances islet function, FEBS Lett., 2008, 582, 23332337.

$50 \mathrm{~J}$. C. Henquin, Triggering and amplifying pathways of regulation of insulin secretion by glucose, Diabetes, 2000, 49, 1751-1760.

51 F. M. Ashcroft and P. Rorsman, Electrophysiology of the pancreatic beta-cell, Prog. Biophys. Mol. Biol., 1989, 54, 87143.

52 H. Steinbrenner, A. L. Hotze, B. Speckmann, A. Pinto, H. Sies, M. Schott, M. Ehlers, W. A. Scherbaum and S. Schinner, Localization and regulation of pancreatic selenoprotein P, J. Mol. Endocrinol., 2012, 50, 31-42.

53 S. S. Yu, L. L. Men, J. L. Wu, L. W. Huang, Q. Xing, J. J. Yao, Y. B. Wang, G. R. Song, H. S. Guo, G. H. Sun, Y. H. Zhang, H. Li and J. L. Du, The source of circulating selenoprotein $\mathrm{S}$ and its association with type 2 diabetes mellitus and atherosclerosis: a preliminary study, Cardiovasc. Diabetol., 2016, 15, 70 . 